\title{
AERODYNAMIC STUDY OF THE WIND FLOW IN THE AREA OF THE R2 EXPRESSWAY IN SLOVAKIA
}

\author{
Olga HUBOVÁ ${ }^{*}$, Marek MACÁK ${ }^{2}$, Alžbeta GRMANOVÁ ${ }^{1}$
}

\begin{abstract}
Our calculation of wind effects was based on the specific wind situation of the planned R2 expressway. Given the topography and the prevailing wind directions, it was necessary to analyse the speeds for winds that could cause vehicles with trailers to be pushed off the roadway, as has been observed in recent years. Using a CFD simulation in the ANSYS FLUENT program, we analysed the entire section of the planned $R 2$ expressway in order to evaluate the wind speeds at the level of the centre of gravity of truck trailers. Statistical turbulence models based on a time-averaging method, i.e., the RANS-Reynolds Averaged Navier-Stokes equations, of turbulent flow quantities and the time-averaging procedure of balance equations are suitable for solving the engineering tasks. In numerical simulations, the Realizable $k$ - $\varepsilon$ model was used in which the calculation of the turbulent dynamic viscosity in the equation for Boussinesque's hypothesis was solved using two transport equations. Plotting and comparing the wind speeds for significant wind directions allowed us to design protection in the dangerous areas using protective walls.
\end{abstract}

Address

1 Dept. of Structural Mechanics, Faculty of Civil Engineering STU, Bratislava, Slovak Republic

1 Dept. of Mathematics and Descriptive Geometry, Faculty of Civil Engineering STU, Bratislava, Slovak Republic

* Corresponding author: olga.hubova@stuba.sk

\section{Key words}

- Wind velocity,

- Wind direction,

- Computational fluid dynamics (CFD),

- Intensity of turbulence,

- Realizable $k-\varepsilon$ model.

\section{INTRODUCTION}

Various windstorms have swept through Slovakia in recent years, and one of them in 2004 destroyed vast forest areas and damaged buildings in the High Tatras. Due to the increase in the number of wind storms recently, where wind speeds in gusts have reached the levels of hurricanes in Slovakia, it has become necessary to pay attention to the need for protection from wind. We see that wind speeds above $32.7 \mathrm{~m} / \mathrm{s}$ or $118 \mathrm{~km} / \mathrm{h}$ are defined as hurricanes on the Beaufort scale. The worst windstorms that have appeared in Western and Central Europe have reached level 12:

In 2007, Kyrill with a maximum wind speed in gusts of $250 \mathrm{~km} / \mathrm{h}$ In 2008, Emma, with a maximum wind speed in gusts of $236 \mathrm{~km} / \mathrm{h}$ In 2010, Xynthia, with a maximum wind speed of $238 \mathrm{~km} / \mathrm{h}$ In 2020, Sabine with a maximum wind speed of $202 \mathrm{~km} / \mathrm{h}$
Wind storms with the power of a hurricane mostly come in the months of February and March and proceed from the west or northwest to Central Europe. Storms passing through Germany and the Czech Republic reduce their speed a bit, but the highest speed values measured in Slovakia during Kyrill and Emma reached a wind speed of $44 \mathrm{~m} / \mathrm{s}$, which also caused significant damage to buildings. Given the changing climate, this trend of windstorms can affect road traffic in a variety of ways. In the most obvious sense they make a motor vehicle difficult to steer and may even overturn it (see https://www. youtube.com $/$ watch? $\mathrm{v}=8 \mathrm{ryaYqXrFnY}$ ). Problems involving vehicle control increase dramatically with rising wind strengths. The force exerted on a vehicle by a crosswind is proportional to the square of the wind's strength, which means that if the wind speed doubles, the pressure exerted on a vehicle by a crosswind becomes four times higher than it was before. When designing an expressway in a specif- 
ic given area, it is necessary to consider the adverse effects of crosswinds and also to consider the local topography, which may cause an increase in the wind speed. Information about wind flow in a specific topographic terrain can be found in the works of (Jackson and Hunt, 1975; Bowen, 1983; Taylor and Lee, 1984). Measures to reduce the adverse effects of strong crosswinds include the construction of artificial windbreaks (Sterling et al. 2010; Chia Chu et al. 2013) or the planting of trees along exposed stretches of a highway. These efforts are often successful and have the added benefit of reducing noise from the motorway in the vicinity. Various ways to protect roads from wind can be found in (Gandemiere 1981), (Chia Chu et al. 2013) and (Paek et al. 2016).

Experimental and numerical - Computational Fluid Dynamics (CFD) research studying the effects of crosswinds can be found in (Kim et al. 2014; Paek et al. 2016). Due to the large side area of a trailer and changing road conditions, the effects of a crosswind on trailer stability have been monitored using numerical CFD simulations (Qianwen Zhang et al. 2020).

In our research, we have monitored the wind flow in a mountainous area, where we assume the prevailing wind directions to be perpendicular to a planned speedway and we can therefore expect increased values in the crosswind speed. The aim is to analyse the wind situation along an $8 \mathrm{~km}$ part of the planned expressway and identify areas of unfavourable crosswinds. We obtained the meteorological and topographical situation of the area, which is defined by the National Annex to the standard STN EN 1991-1-4 (2007), and also the prevailing wind flow directions, which are defined in (Polčák and Št’astný 2010).

\section{WIND FLOW}

The effects of wind flows are set out in EN 1991-1-4 (2007) and the National Annex STN EN 1991-1-4 /NA (2007). Wind speed calculations are based on the specific wind situation in a given area. The following factors affect the resulting wind speed values:

$1 /$ site-specific wind conditions,

$2 /$ roughness of the terrain,

3 aerodynamic characteristics of the shape of an object,

4/ surrounding structures.
Wind flows belong in the field of aerodynamics. Peak wind pressures are defined based on long-term meteorological measurements. In terms of wind flow, air can be considered an ideal and incompressible fluid with low resistance. The character of the wind flow around structures is determined by the Reynolds number:

$$
\operatorname{Re}=d \cdot v / v
$$

where $d$ - is the characteristic size of the structure, $v$ - is the flow velocity, $v=1.5 \cdot 10^{-5}\left[\mathrm{~m}^{2} / \mathrm{s}\right]$ - is the kinematic viscosity.

\subsection{Basic characteristics of natural wind}

A built-up area where the wind velocity equalizes from zero to the value of the respective potential flow is called the boundary layer and ranges from 300 to $600 \mathrm{~m}$, depending on the roughness of the terrain. The wind flow in the boundary layer is turbulent. The basic characteristics of the wind are as follows:

1 / wind direction, which can express the prevailing wind direction in a given area. For some areas, the wind direction roses are processed from the measurements. Based on the publication The Effect of Reliefs on the Wind Conditions of the Slovak Republic (Polčák and Št'astný, 2010), the following dominant wind directions were considered in the area of the R2 expressway (see Fig. 1), namely, north, northeast, northwest, south, southeast and southwest (see Figs. 2a - 2b).

2 / the basic wind speed $v_{\mathrm{b}}$ is influenced by the wind direction and also by the season.

It is determined from the fundamental value of the basic reference speed $v_{\mathrm{b}, 0}$, which is the characteristic value of a strong wind lasting for 10 minutes regardless of the wind direction. This is measured by hydrometeorological institutes at automatic synoptic stations. Universal anemographs record wind speeds and wind directions in digital form at 2-second intervals at a height of $10 \mathrm{~m}$ above the ground in a flat open terrain (Terrain Category II).

$$
v_{\mathrm{b}}=c_{\mathrm{dir}} \cdot c_{\text {season }} \cdot v_{\mathrm{b}, 0}
$$

where $c_{\text {dir }}[-]$ is the directional factor; $c_{\text {season }}[-]$ is the seasonal factor; and $v_{\mathrm{b}, 0}[\mathrm{~m} / \mathrm{s}]$ is the basic reference wind speed in the area.

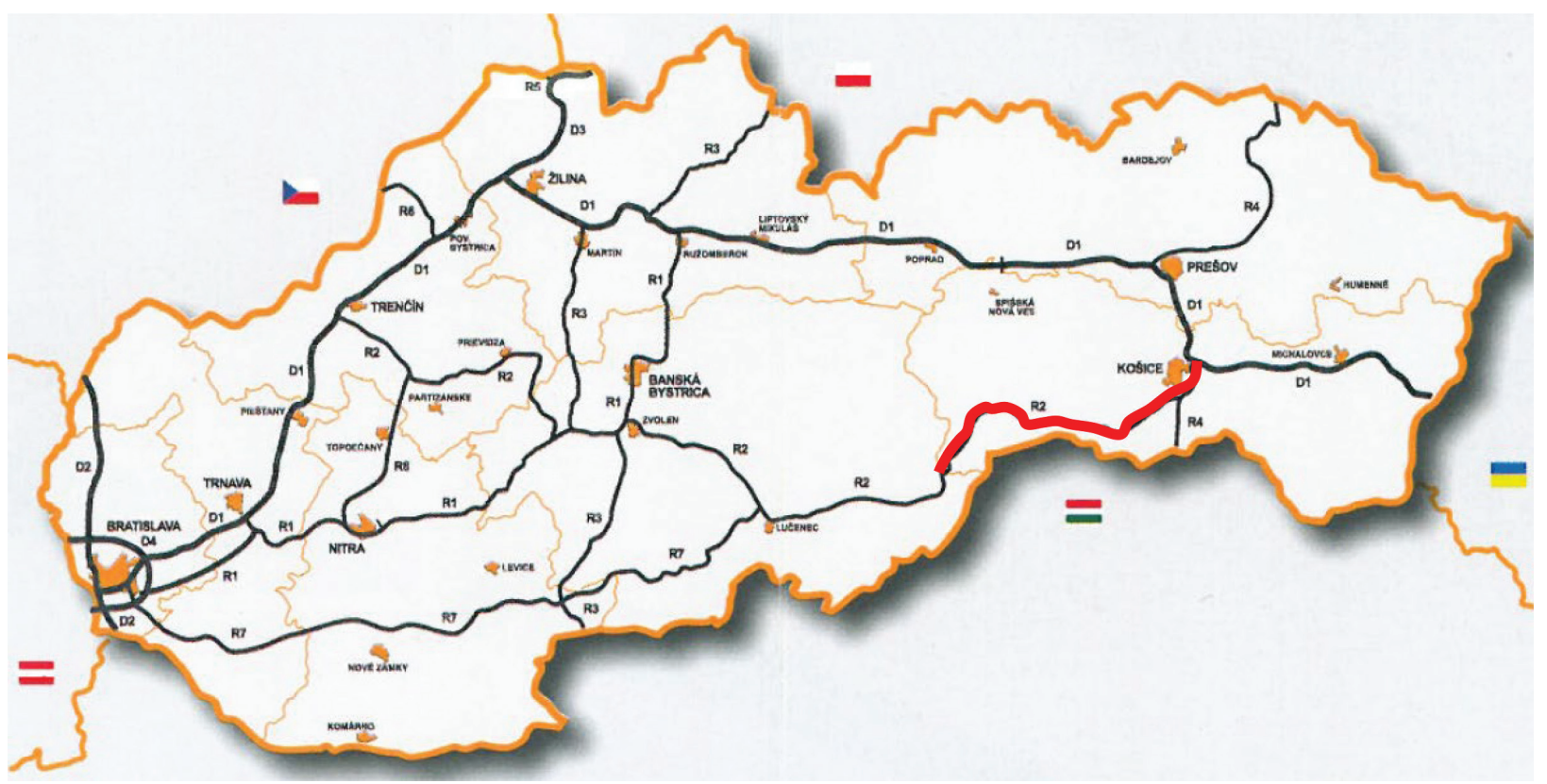

Fig. 1 Area of the planned R2 expressway in Slovakia (red line) 


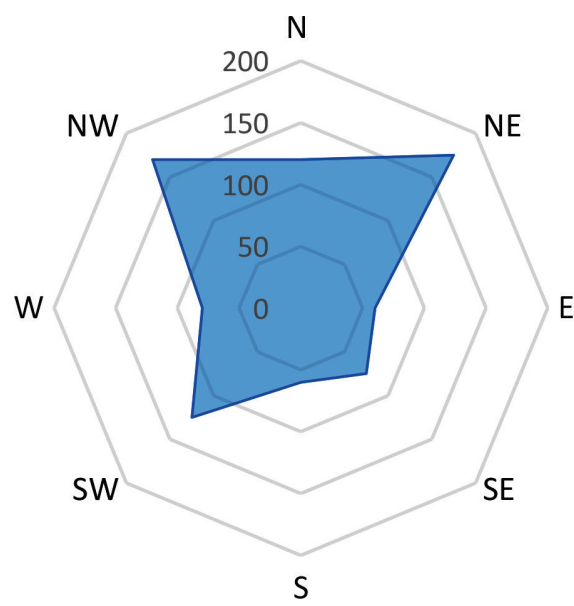

Fig. 2a The frequency of wind directions in parts per thousand in Rožňava

3 / the mean wind speed $v_{m}$ at height $z$ above the ground is determined as follows:

$$
v_{m}(z, t)=\frac{1}{T} \int_{0}^{T} v(z, t) d t=v_{m}(z)
$$

The gradient function of the mean wind speed according to (EN 1991-1-4, 2007) is expressed by a logarithmic function, depending on the roughness length $z_{0}$ of the given terrain:

$$
\begin{gathered}
v_{m}(z)=c_{r}(z) \cdot c_{o}(z) \cdot v_{\mathrm{b}}=k_{r} \cdot \ln \left(z / z_{0}\right) \cdot 1 \cdot v_{\mathrm{b}}= \\
=0.19\left(z / z_{0, \mathrm{II}}\right)^{0,07} \ln \left(z / z_{0}\right) \cdot v_{\mathrm{b}}
\end{gathered}
$$

Experimental measurements on the Earth's surface in the atmospheric boundary layer determine the values of the roughness length of the surface $z_{0}$, which is the value corresponding to the extrapolation of the logarithmic function to a zero wind speed for the different terrain types (see Table 1).

$4 /$ the intensity of the turbulence is defined by the ratio $\sigma_{v} / v_{\mathrm{m}}(\mathrm{z})$, where $\sigma_{\mathrm{v}}$ is the standard deviation of the wind speed fluctuation component $v(z, t)$. The intensity of the turbulence (5) decreases with the height above the terrain; thus, the effect of the dynamic load decreases. In Fig. 3, it is possible to see the intensity of the turbulence as defined in EN 1991-1-4 (2007):

$$
I_{v}(z)=\frac{k_{I}}{c_{0}(z) \cdot \ln \left(z / z_{0}\right)}=\frac{1}{1 \cdot \ln \left(z / z_{0}\right)}
$$

for $z_{\min } \leq z \leq z_{\max }$

\subsection{Wind characteristics in the area of the R2 expressway}

According to EN 1991-1-4 and the national annex of Slovakia STN EN 1991-1-4/NA (2007), the value of the reference wind speed

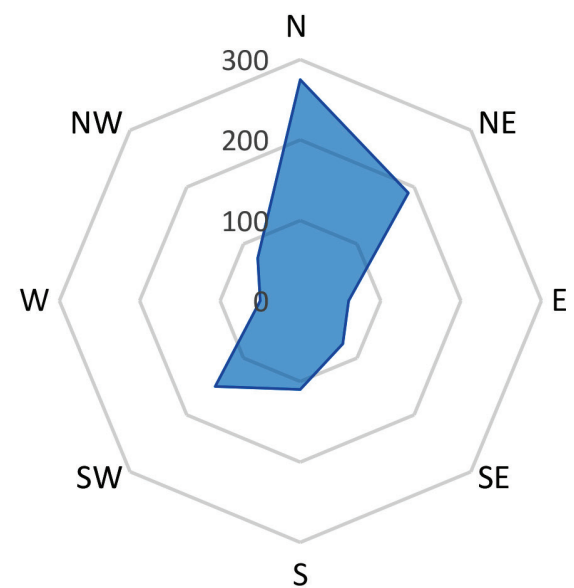

Fig. 2b The frequency of wind directions in parts per thousand in Košice

Intensity of turbulence

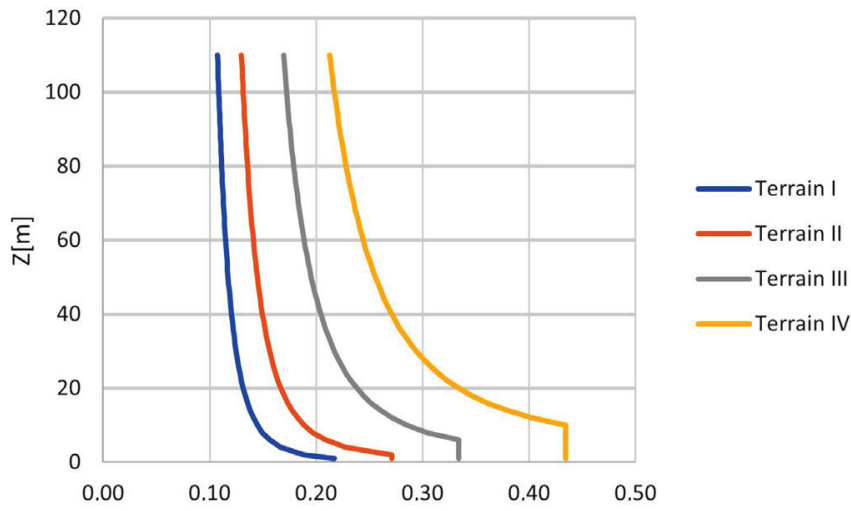

Fig. 3 Intensity of turbulence according to EN 1991-1-4 for the different terrain categories

is given by formula (2), and $v_{\mathrm{b}, 0}=26[\mathrm{~m} / \mathrm{s}]$ is the fundamental value of the wind speed in the area between Rožn̆ava and Košice (see Fig. 1). The directional and seasonal factors can be considered equal to 1 . In the area of the expressway, there are continuous forests from the north, so we can consider the terrain to belong to category III; from the south, there is an open landscape that corresponds to terrain category II.

\section{NUMERICAL SIMULATION OF THE WIND EFFECTS}

The aim of the numerical simulation was to define the critical

\begin{tabular}{|c|c|c|c|}
\hline Terrain category & $z_{0}[\mathrm{~m}]$ & $z_{\min }[\mathrm{m}]$ & $k_{r}$ \\
\hline 0 - Sea or coastal area exposed to the open sea & 0.003 & 1 & 0.156 \\
\hline I - Lakes or flat and horizontal area without obstacles & 0.01 & 1 & 0.1697 \\
\hline II - Area with low vegetation such as grass and isolated obstacles & 0.05 & 2 & 0.19 \\
\hline III - Area with a regular cover of vegetation or buildings (villages, suburban terrain, permanent forest) & 0.3 & 5 & 0.215 \\
\hline IV - Area in which at least $15 \%$ is covered with buildings, and their average height exceeds $15 \mathrm{~m}$ (city centre) & 1.0 & 10 & 0.234 \\
\hline
\end{tabular}
wind speeds for the dominant wind directions on the expressway at a height of about $2.5 \mathrm{~m}$, which is the level of the centre of gravity of

Table 1 Terrain category according to EN 1991-1-4 
various types of heavy freight transport. For the analysis of the problem to be solved, we chose the finite volume method implemented into the ANSYS Fluent $(2017,2018)$ program, which offers several turbulence models.

In this article we present a preliminary modelling of the wind flow on the site of the R2 expressway in Slovakia, which outlines the distribution of the wind speed along the road. The results of the CFD study help identify the areas along the road where measures are needed to reduce the adverse effects of wind.

\subsection{Numerical model}

The numerical simulation was made with the ANSYS Fluent $(2017,2018)$ program, which allows for a detailed definition of the problem and its solution and contains the most comprehensive set of mathematical models used in many applications.

The computer fluid simulation for the problem on a scale of $1: 1$ was prepared. For the solution of the 3D steady RANS equations with a standard $k-\varepsilon$ model (Wilcox, 1986), we used the ANSYS Fluent CFD code, which solves Navier - Stokes equations along with the two equations added.

The Realizable $k-\varepsilon$ model selected solves the transport equation for the transfer of turbulent kinetic energy $k$ in the form:

$$
\frac{\partial}{\partial t}(\rho k)+\frac{\partial}{\partial x_{i}}\left(\rho k u_{i}\right)=\frac{\partial}{\partial x_{j}}\left[\left(\mu+\frac{\mu_{t}}{\sigma_{k}}\right) \frac{\partial k}{\partial x_{j}}\right]+G_{k}-\rho \varepsilon
$$

and the transport equation for the transfer of the rate of dissipation of the turbulent kinetic $\varepsilon$ :

$$
\frac{\partial}{\partial t}(\rho \varepsilon)+\frac{\partial}{\partial x_{i}}\left(\rho \varepsilon u_{i}\right)=\frac{\partial}{\partial x_{j}}\left[\left(\mu+\frac{\mu_{t}}{\sigma_{\varepsilon}}\right) \frac{\partial \varepsilon}{\partial x_{j}}\right]+\rho C_{1} S \varepsilon-C_{2} \rho \frac{\varepsilon^{2}}{k+\sqrt{ }}
$$

where $u$ is the wind speed $[\mathrm{m} / \mathrm{s}] ; t$ is the time $[\mathrm{s}] ; k$ is the turbulent kinetic energy $\left[\mathrm{m}^{2} / \mathrm{s}^{2}\right] ; \varepsilon$ is the dissipation of the turbulent kinetic energy $\left[\mathrm{m}^{2} / \mathrm{s}^{3}\right] ; \mu_{t}$ is the turbulent dynamic viscosity $[\mathrm{kg} / \mathrm{m} . \mathrm{s}] ; v$ is the kinematic viscosity $\left[\mathrm{m}^{2} / \mathrm{s}\right] ; \sigma$ is the turbulent Prandtl number [-]; $G_{k}$ expresses the change in the turbulent kinetic energy due to the change in the velocity gradient; $\rho C_{1} S \varepsilon$ is the production member; $C_{2}$ is the model constant; and $\rho$ is the air density $\left[\mathrm{kg} / \mathrm{m}^{3}\right]$.

This turbulent model is characterized by a high degree of accuracy near walls, while its accuracy in an open terrain is average.

\subsection{Computational domain}

The computational model was created based on the actual topography in the area of interest. The terrain in the area of the expressway is shown in Fig. 4.

The size of the computational domain was $50 \times 26 \times 7 \mathrm{~km}^{3}(1 \times \mathrm{W} \times \mathrm{h})$ according to the recommended maximum value of block ratio $3 \%$ (Franke, 2007; Blocken 2007, 2015). An illustration of the area of the calculations is shown in Fig. 5.

\subsection{Computational grid (mesh)}

The computational mesh was generated using polyhedral elements. The size of the elements on the terrain was $20 \mathrm{~m}$. The size of the elements was set at $10 \mathrm{~m}$ in the vicinity of the R2 expressway. On the bottom of the boundary layer, the function of inflation was applied with 5 layers, with $0.5 \mathrm{~m}$ as the height of the first layer according to Franke (2007) and Blocken (2007, 2015). A total of 25033591 nodes were generated. An illustration of the computational grid is shown in Fig. 6 and the details of the mesh are in Fig. 7.

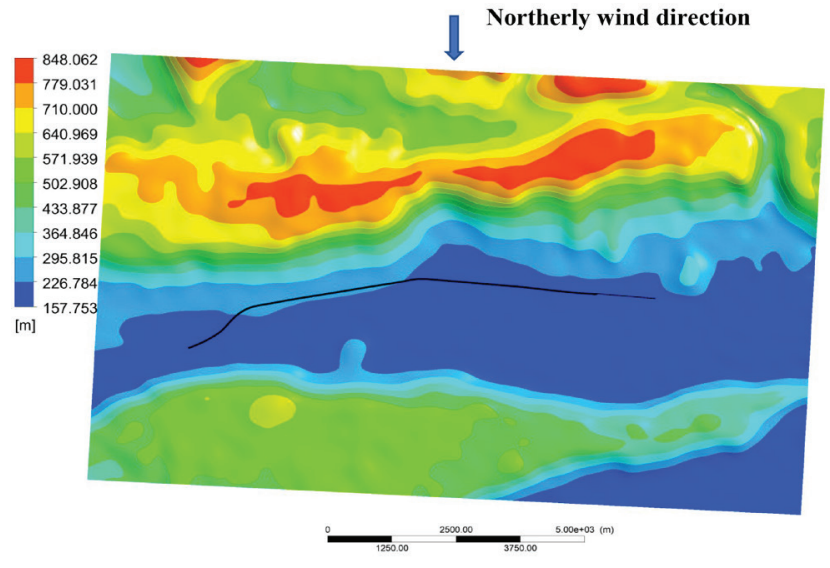

Fig. 4 Terrain in the area of the $R 2$ expressway

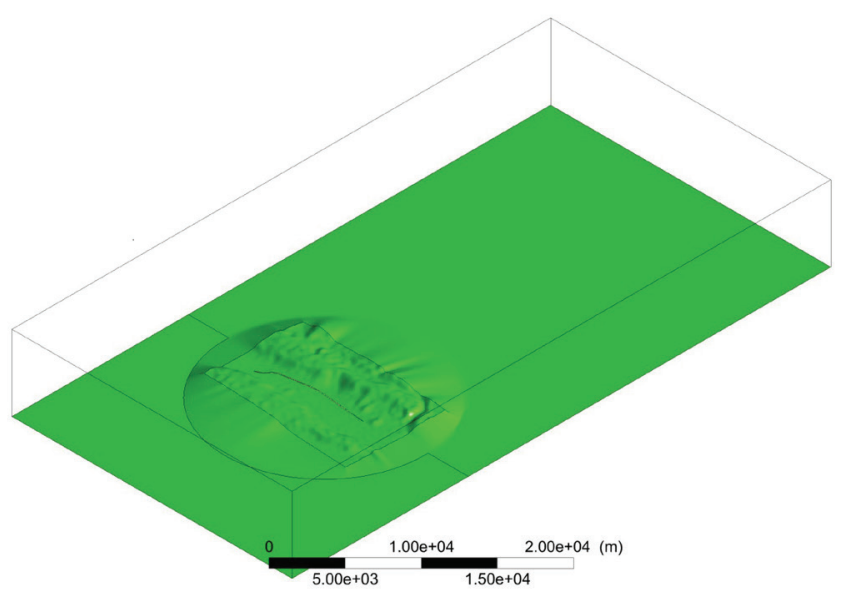

Fig. 5 Illustration of the computation domain in ANSYS Fluent

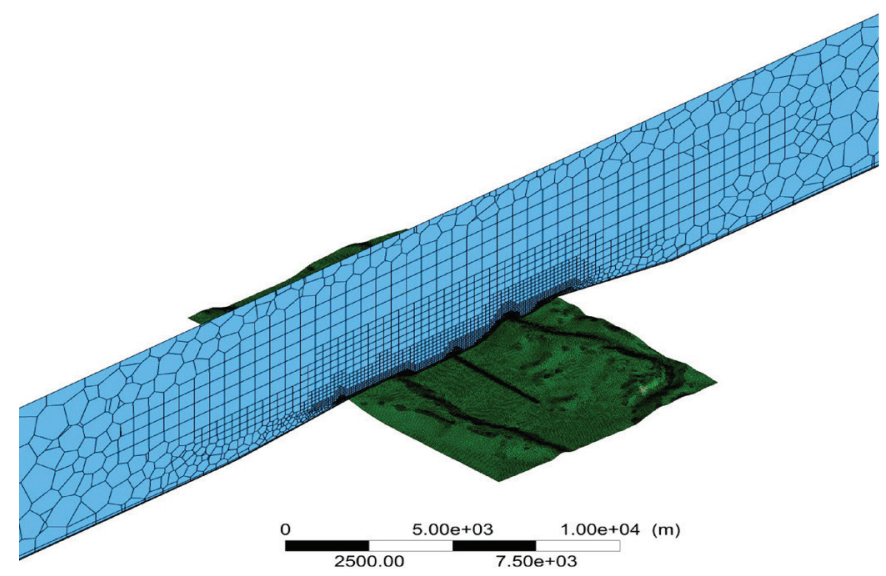

Fig. 6 Computational grid

\subsection{Boundary conditions}

The inlet boundary condition of the domain was defined by the vertical profiles

$$
v(z)=\frac{v^{*}}{\kappa} \ln \frac{z+z_{0}}{z_{0}}, v^{*}=\frac{v_{r e f} \kappa}{\ln \frac{z_{r e f}+z_{0}}{z_{0}}},
$$

where $v(z)$ is the mean wind velocity at height $z ; v^{*}$ is the shear velocity; $z_{0}$ is the aerodynamic roughness length $\left(z_{0}=0.3\right.$ for terrain cat. III and $z_{0}=0.05$ terrain cat. II); $\kappa$ is the von Karman constant $(\kappa=0.42)$; 
and $v_{\text {ref }}=26 \mathrm{~m} / \mathrm{s}$ is the reference wind speed that was considered at $10 \mathrm{~m}$ above ground level (see STN EN 1991-1-4/NA, 2007).

The turbulence at the entrance to the computational area was modelled using the relationships:

$$
k=\frac{u^{* 2}}{\sqrt{c_{\mu}}}, \varepsilon(z)=\frac{u^{* 3}}{\kappa\left(z+z_{0}\right)},
$$

$C_{\mu}=0.09$ is a model constant. These boundary conditions create a wind and turbulence profile that is identical to the one in EN 1991-1-4.

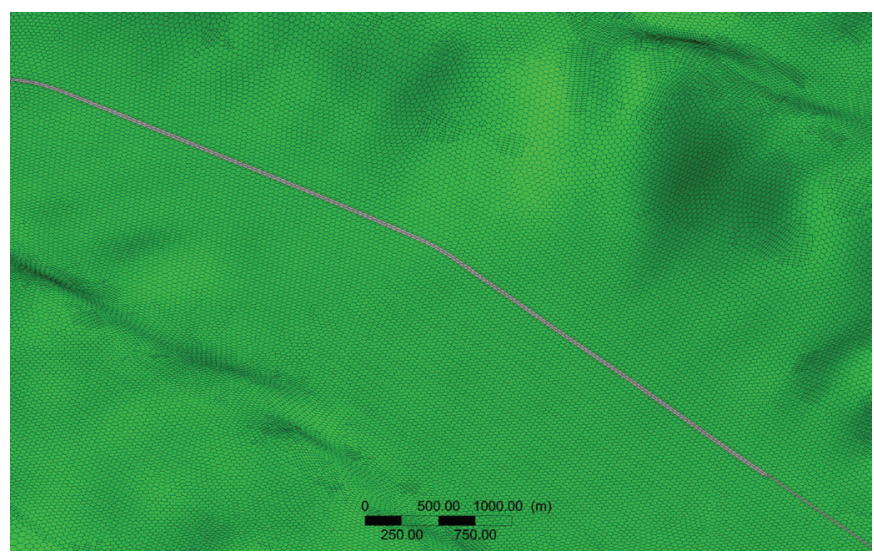

Fig. 7 Detail of the computation grid

The profile of the wind speed and turbulence for terrain category III (permanent forest) and their comparison with EN 1991-1-4 can be seen in Fig. 8.
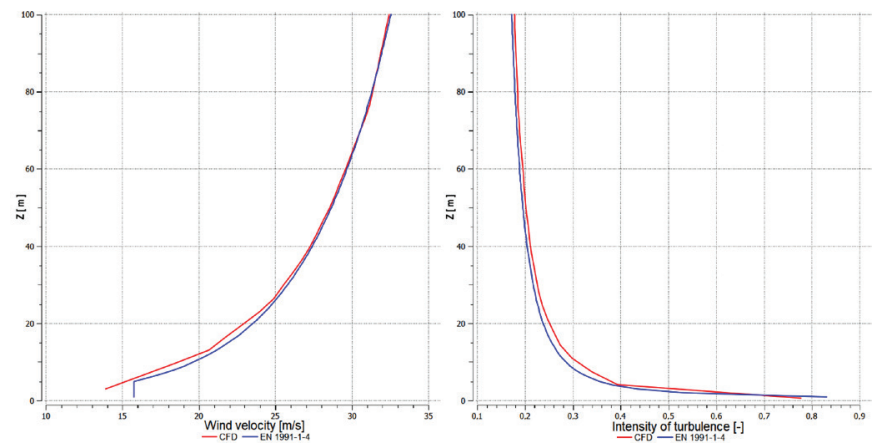

Fig. 8 Wind velocity and turbulence profile for terrain category III

The outlet boundary is defined as the pressure outflow and the side and upper boundaries as a zero gradient (symmetry).

\section{RESULTS AND DISCUSSION}

Due to the approach of RANS modelling and the turbulent model Realizable $k-\varepsilon$ used in the numerical simulation, the outputs were the average values of the wind speeds at the individual calculation points of the network.

\subsection{Wind flow above the $\mathrm{R} 2$ expressway}

The R2 expressway runs from the west to the east. In the past the adverse effects of crosswinds, which are dangerous for empty truck trailers, have been observed in the area. We tested the effects of wind flowing from the north and south, which are the most unfavourable directions. The modelled section of the road was $8000 \mathrm{~m}$ long.

\subsection{Evaluation of the wind speed at a height of $2.5 \mathrm{~m}$ above the expressway}

The methodology used in this study was as follows:

The wind speeds at level $2.5 \mathrm{~m}$ above the planned speedway were evaluated. This height is the centre of gravity of truck trailers. The values of the wind speeds along the road were evaluated. We assumed a flow from the north and considered the terrain of a continuous forest, which is category III, and also with the topography of a northern area, which is mountainous. In the case of a wind flow from the south, we assumed a starting wind flow through an open terrain (terrain category II), as well as the topography that modifies the flow from the south. The wind direction from the north was considered to be $0^{\circ}$ and $180^{\circ}$ from the south. Due to the prevailing wind directions according to the wind rose, the wind directions were also evaluated with a step of $22.5^{\circ}$.

Some results of the dangerous wind flow over the given area are plotted in Figs. 9a-11a, and the details of the wind speed at a height $2.5 \mathrm{~m}$ above the $\mathrm{R} 2$ is plotted in Figs. $9 \mathrm{~b}-11 \mathrm{~b}$.

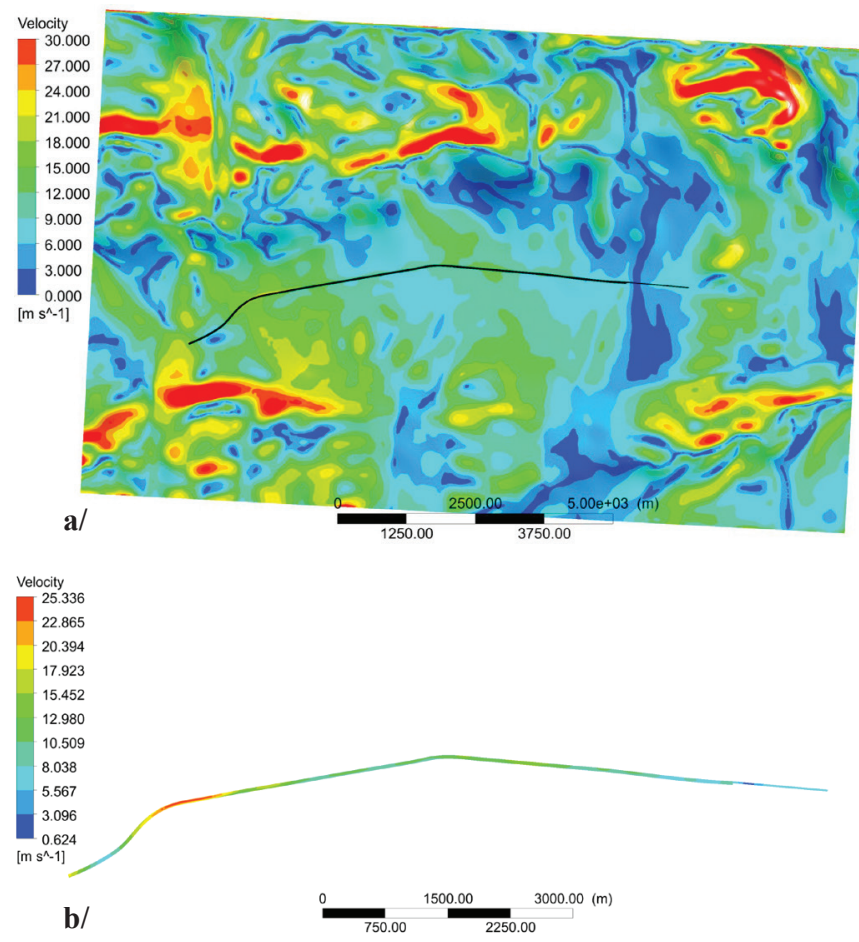

Fig. 9 a/ Wind distribution above the area - wind direction $0^{\circ}$ b/ details of the expressway

The unfavourable wind speeds at a height $2.5 \mathrm{~m}$ above the expressway in some sections are higher than the reference wind speed of $26 \mathrm{~m} / \mathrm{s}$, which is considered at a height $10 \mathrm{~m}$ above the open terrain. The dangerous sections of the expressway are marked in red.

\subsection{Focusing on the dangerous values of crosswind speeds}

A detailed analysis of the wind speed in the planned section of the R2 expressway, especially considering the wind flow from the north and south, which may cause problems for vehicles, showed us the areas where it is necessary to protect vehicles passing through the area. The results of the computer simulation for the different flow directions from the north and south are shown in the graphs in Figs. 12 and 13. 

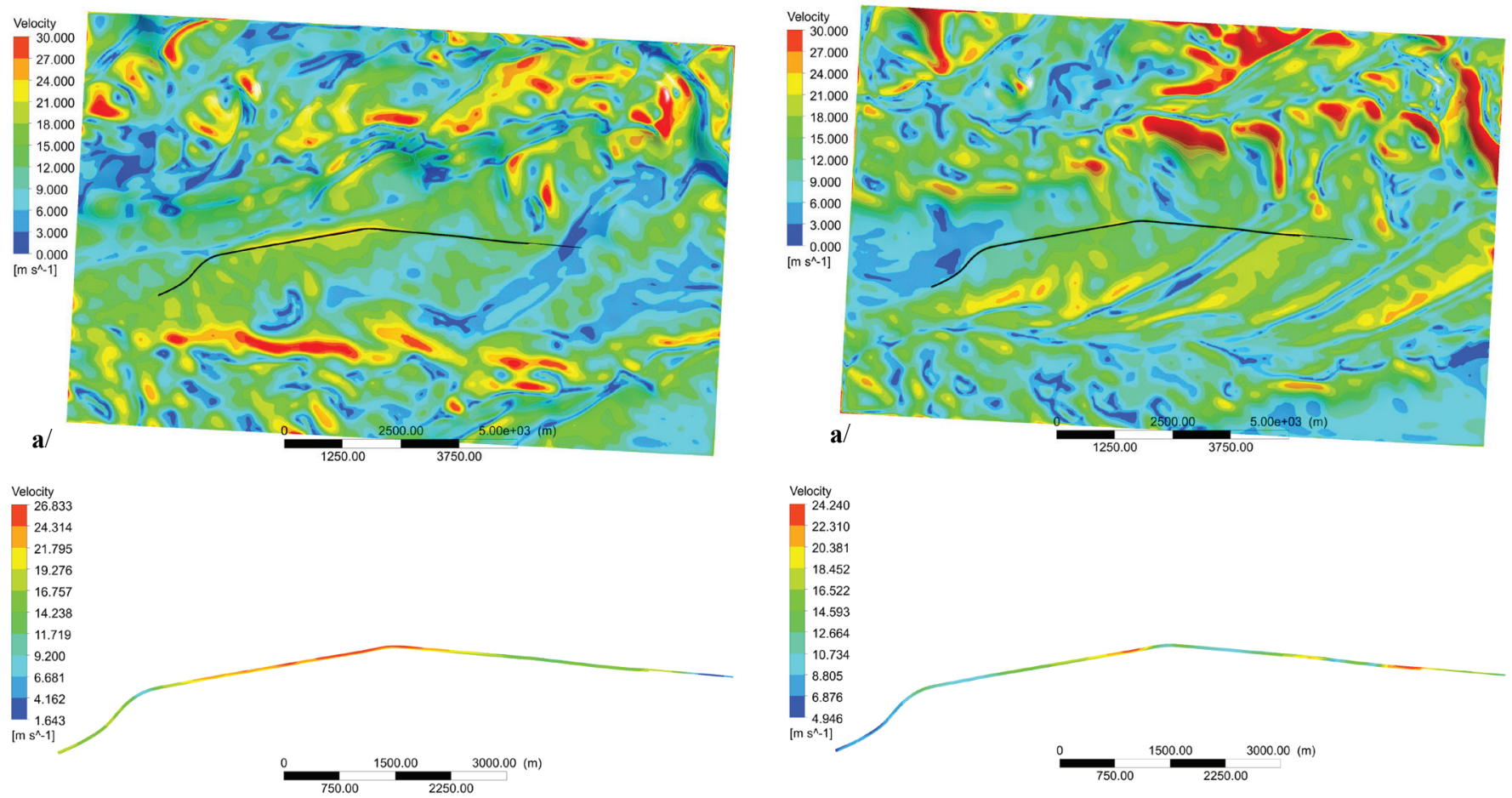

b/

b/

Fig. 10 a/ Wind distribution above the area - wind direction $45^{\circ}$ b/ details of the expressway

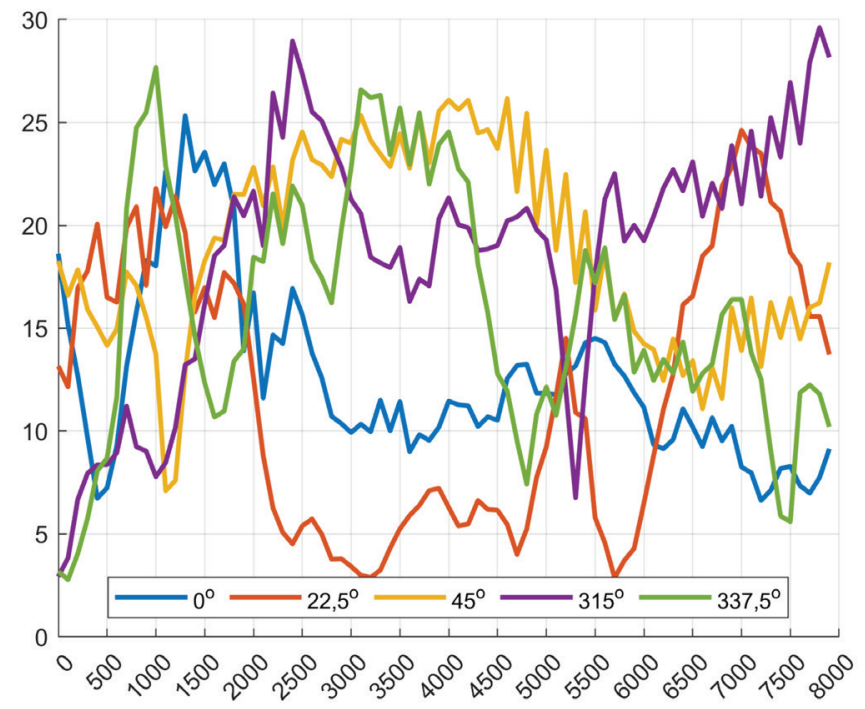

Fig. 12 Wind speeds along the R2 expressway for different wind directions from the north

\section{CONCLUSIONS}

Based on the numerical computation simulation (CFD) of the wind flow in the ANSYS program in the given area, and considering the different wind directions from the north and south, we can draw the following conclusions:

The most dangerous areas along the expressway appear to be from the northwest wind flow - wind direction $315^{\circ}$ and $337.5^{\circ}$.

During this wind flow, there are sections of the expressway where the wind speed at the centre of gravity of the truck trailers exceeds $25 \mathrm{~m} / \mathrm{s}$.

Fig. 11 a/ Wind distribution above the area - wind direction $225^{\circ}$ $\mathbf{b} /$ details of the $R 2$ expressway

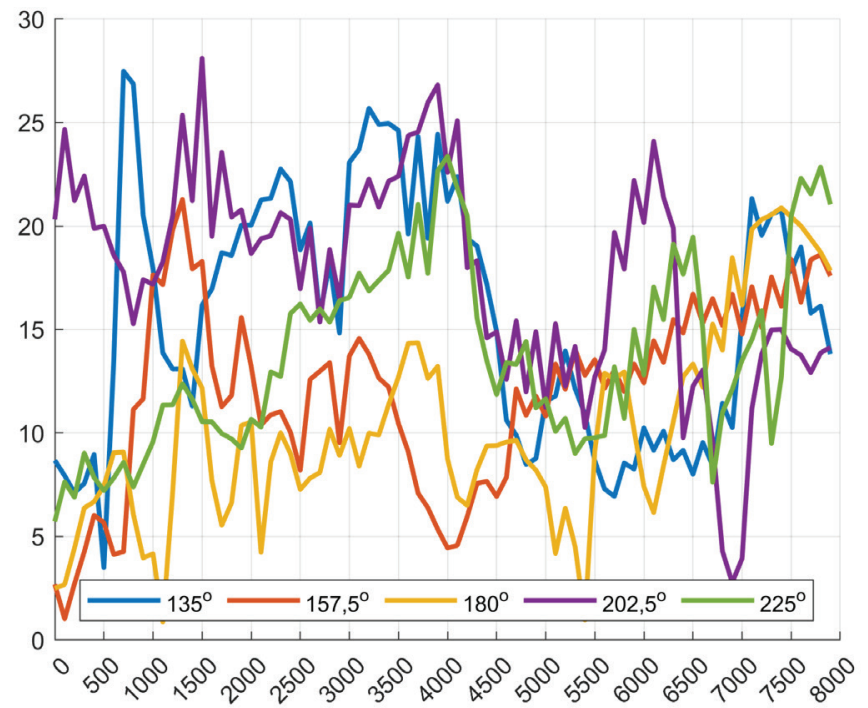

Fig. 13 Wind speeds along the R2 expressway for different wind directions from the south

In the southern wind flow, the unfavourable wind directions are southeast $-135^{\circ}$ and southwest $-202.5^{\circ}$.

Due to the prevailing wind directions according to the wind roses (see Figs. 2a-2b) located in the area, the most unfavourable situation would be with the northwest wind direction $-315^{\circ}$ and the southwest wind direction $-202.5^{\circ}$.

Due to the fact that there are strong wind storms in Slovakia in the months of February and March and also in November, it will not be enough to plant trees along the expressway. This area is dominated by deciduous trees, which do not have leaves at that time and therefore cannot significantly reduce the crosswind. 
The use of wind barriers in the form of walls with openings in the first kilometre and between the second and third kilometres of the planned expressway as well as at the end of the R2, between the seventh and eighth kilometres seems to be the most appropriate option.

\section{Acknowledgments}

This research was supported by the Slovak Scientific Grant Agency of the Ministry of Education, Science, Research and Sport of the Slovak Republic, the Slovak Academy of Sciences Projects VEGA No. 1/0412/18 and No. 1/0453/20, and by the Slovak Research and Development Agency under Contract No. APVV-19-0460.

\section{REFERENCES}

ANSYS Inc. (2017) ANSYS Fluent Theory Guide, Release 18.1

ANSYS Inc. (2018) ANSYS Fluent User's Guide, Release 19.1

Blocken, B. - Stathopoulos T. - Carmeliet J. (2007) CFD simulation of the atmospheric boundary layer-wall function problems. Atmospheric Environment 41(2):238-252, Elsevier.

Blocken, B. (2015) Computational Fluid Dynamics for urban physics: Importance, scales, possibilities, limitations and ten tips and tricks towards accurate and reliable simulations. Journal of Building and Environment, [online]. vol. 91, pp. 219-245. Available on: https://doi.org/10.1016/j.buildenv 2015.02.15.

Bowen, A. J. (1983) The prediction of mean wind speeds above simple 2-D hill shapes, JWEIA, 15, pp. 259- 270.

Chu, Ch. - Chang, CH. Y. - Huang, Ch. J. - Wu, T. R. - Wang, CH. Y. - Liu, M. Y. (2013) Windbreak protection for road vehi-cles against crosswind, Journal of Wind Engineering and Industrial Aerodynamics 116:61-69.

Davenport, A. G. (1964) Note on the distribution of the largest value of random function with application to gust loading. Institution of Civil Engineers, vol. 28, No. 6739, pp. 187-196.

EN 1991-1-4 (2007) Eurocode 1. Actions on structures. Part 1-4: General actions. Wind actions.

Franke, J. - Baklanov, A. (2007) Best practice guideline for the CFD simulation of flows in the urban environment, COST Office, Brussels, Belgium.

Gandemier, J. - Guyot, A. (1981) La protection contre de vent, Centre scientifique et technique du batiment, Paris.

Jackson, P. S. - Hunt, J. C. R. (1975) Turbulent flow over a low hill, QJRMS, 101, pp. 929-955.

Kim, Y. M. - You, K. P. - You, J. Y. (2014) Characteristics of wind velocity and temperature change near an escarpment-shaped road embankment, The Scientific World J, 2014, pp.1-13.
Paek, S. Y. - Nam, B. H. - Kim, Y. M. - You, K. P. - You, J. Y. (2016) Study on Wind Flow around Highway Embankments, MATEC Web of Conferences DOI: 10.1051/ 56, 08004 ) matec 56 conf/2016 0 ICCAE 20164.

Polčák, N. - Št’astný, P. (2010) Vplyv reliéfu na veterné pomery Slovenskej republiky (The Effect of Reliefs on the Wind Conditions of the Slovak Republic), Slovak Hydrometeorological Institute and Matej Bel University, Banská Bystrica, Slovakia.

Sterling, M. - Quinn, A. D. - Hargreaves, D. M. - Cheli, F. - Sabbiono, E. - Tamasini, G. - Delaunay, D. - Baker, C. J. Mor-van, H. (2010) A comparison of different methods to evaluate the wind induced forces on a high-sided lorry, Journal of Wind Engineering and Industrial Aerodynamics 98(1): 10-20.

STN EN 1991-1-4/NA (2007) Eurocode 1. Actions on structures. Part 1-4: General actions. Wind actions, National Annex.

Tayor, P. A. - Lee, R. J. (1984) Simple guidelines for estimating wind speed variations due to small scale topographic features, Climatological Bulletin (Canada), 18(2), pp. 3-32.

Wilcox, D. C. (1986) Multiscale model for turbulent flows, In: AIAA 24th Aerospace Sciences Meeting. American Institute of Aeronautics, ISBN: 978-1-84821-001-1.

Zhang, Q. - Su, C. - Zhou, Y. - Zhang, C. - Ding, J. - Wang, Y. (2020) Numerical investigation on handling stability of a heavy tractor semi-trailers under crosswind, of a heavy tractor semi-trailers under crosswind, Applied Scienc-es, vol. 10, 3672; doi: 10.3390. 